\section{$\underset{\substack{\text { hommes } \\ \text { \& migrations }}}{ }$}

\section{Hommes \& migrations}

Revue française de référence sur les dynamiques

migratoires

$1300 \mid 2012$

Nouveaux modèles migratoires en Méditerranée

\title{
Sandrine Charlemagne, Mon pays étranger
}

La Différence, 2012, 251 pages, 18 euros

\section{Mustapha Harzoune}

\section{Q OpenEdition}

\section{Journals}

\section{Édition électronique}

URL : http://journals.openedition.org/hommesmigrations/957

DOI : $10.4000 /$ hommesmigrations.957

ISSN : 2262-3353

Éditeur

Musée national de l'histoire de l'immigration

\section{Édition imprimée}

Date de publication : 1 novembre 2012

Pagination : 163-164

ISSN : 1142-852X

\section{Référence électronique}

Mustapha Harzoune, "Sandrine Charlemagne, Mon pays étranger », Hommes \& migrations [En ligne], 1300 | 2012, mis en ligne le 29 mai 2013, consulté le 22 septembre 2020. URL : http:// journals.openedition.org/hommesmigrations/957 ; DOI : https://doi.org/10.4000/hommesmigrations. 957

Ce document a été généré automatiquement le 22 septembre 2020.

Tous droits réservés 


\section{Sandrine Charlemagne, Mon pays étranger}

La Différence, 2012, 251 pages, 18 euros

Mustapha Harzoune

\section{RÉFÉRENCE}

Sandrine Charlemagne, Mon pays étranger, La Différence, 2012, 251 pages, 18 euros

1 Comédienne, Sandrine Charlemagne dirige une troupe de théâtre et coordonne le projet "Passeurs de mémoires" au sein de l'Association des travailleurs maghrébins de France. Après un premier livre, À corps perdus (Lattès, 1994), elle raconte ici son voyage en Algérie, son "baptême", survenu en 2000, au moment où le pays était encore englué dans les horreurs de la "décennie noire". Née d'un père algérien et d'une mère française, Sandrine Charlemagne écrit sur le mode de la confidence, sans tricher, des pages fortes, tout en tension. Fragile, elle déambule dans les méandres des identités mêlées, en quête de reconstruction et de paix intérieure. Elle découvre un pays, avec sa part de spontanéité, de disponibilité, d'émerveillement, de naïveté aussi, sans oublier, ici ou là, une pugnacité nourrie du courroux de l'antiracisme, du féminisme, d'une soif de justice et de vie.

2 À Alger et à Sidi Bel Abbès, Mahmoud sera son cicérone. Acteur de renom et directeur de théâtre dans la ville qui a vu naître un Marcel Cerdan ou un Kad Merad, mais aussi Djilali Liabes assassiné en 1993, Mahmoud fait découvrir à son hôte sa cité et quelquesuns de ses lieux interlopes, lui présente ses compagnons de fortune, de beuverie, d'espoir et d'amertume. À Oran, elle est accueillie par Amina. Depuis l'assassinat de son mari en 1994, Amina élève seule Farah, sa fille, et Nawel, sa fille adoptive. Grâce à ces rencontres, Sandrine découvre les tourments d'un peuple "fier" et digne. À Boualem qui souhaite partir en France, Amina parle du racisme, des difficultés pour les immigrés et plus encore pour les sans-papiers... Lui évoque l'Algérie et bouscule ses "rêves". " Censures. Ostracisme. Politique roublarde. Ce pays serait-il si différent de ce que j'en aurai 
rêvé ?" Nawel voudrait épouser un émigré. En Algérie, elle est, et restera, une "bâtarde", une fille sans père... No future! "Je ne veux plus entendre parler de l'autre côté de la mer aujourd'hui. Sinon tu n'es plus ma scur", lui lance Farah autant par dépit que par fidélité à son père assassiné. Si les massacres continuent, pour Mahmoud il ne faudrait pas résumer son pays à cette violence : "Tous ces amalgames, j'en ai vraiment ma claque!(...) Toi en France, il faudra les convaincre."

"Je voudrais comprendre ce peuple. Savoir quoi faire de la moitié de mon sang." Cette moitié d'elle-même, longtemps elle en fut privée, comme dépossédée. "Acte de naissance : père inconnu, mère française." Après l'accouchement, le "pater" lâche : "Une fille ? C'est bon pour la poubelle!" La culpabilité et les regrets de l'enfant tourmentent encore l'adulte tout au long de son périple algérien. Elle se rebiffe, se révolte: "Va-t'en, pater-noster, toi et ton crâne en putréfaction! Non, il ne détruira pas mon premier jour ici." Le spectre du "pater", tyrannique et violent, mort cinq ans plus tôt, ne gâchera pas la réconciliation de sa fille avec elle-même et avec son histoire. C'est dans la recherche de l'apaisement, l'effort pour "comprendre", que Malika-Sandrine s'aventure sur le chemin de la résilience: " Sous l'effet du soleil, je reçois dans les yeux des myriades de paillettes. Ces paillettes ce sont des larmes sur la tombe du pater. Larmes qui auraient pu effacer tout ce qui nous a séparés. Larmes que j'aurais voulu verser, blottie seulement un jour entre ses bras." "Je voudrais tant devenir algérienne. Aurais-je alors le sentiment de n'être plus chassée de nulle part?" demande Sandrine, qui découvre un pays, sa lumière, son soleil, le bleu du ciel, le goût de la loubia mais aussi la chaleur et l'hospitalité des Algériens, la simplicité des relations, l'offrande comme marque (désintéressée) de bienvenue, l'alcool aussi que l'on verse ad libitum et en catimini... "Je veux connaître les germes de cette terre, rencontrer la grâce fondamentale. Lave-moi. Revêts-moi d'un nouvel habit. Toi seule me ranimeras."

Quand Mahmoud la présente comme "la Française", cela la gêne, l'embarrasse. Pourtant, plus d'une fois elle sera renvoyée à sa francité, ici elle est aussi une "gaouria", une Française à qui l'on autorise des comportements ou l'accès à des lieux tout simplement impensables pour une Algérienne. "Dans ma présence, il y a de l'interdit", écrit-elle. Elle observe les attitudes, suppute les "méandres" et la "névrose" d'une société où les hommes arborent des "yeux pareils à ceux des loups". Et que valent ses questions identitaires quand, pour certaines femmes qu'elle croise, ce qui se joue, c'est la vie ou la mort?

"Quelle histoire je viens recueillir ici? Celle d'un passé fait de douloureuses blessures? Celle d'un présent se débattant dans le chaos? Comment recevra-t-on ma curiosité de femme à double identité ? Je ne sais quelle réconciliation j'espère." Ces questions, nombreux sont les auteurs à se les être posées, à avoir entrepris cette quête sur une terre où repose le père ou une terre où se niche une part de soi-même (voir Saïd Mohamed, Kazio Ishiguro, Nabil Louaar, Nor Eddine Boudjedia, Mélina Gazsi, Tassadit Imache, Neil Bissoondath, Ook Chung, Fawaz Hussain... ). Ce voyage semble nécessaire pour se réapproprier une part de son histoire, reconstruire le puzzle des identités plurielles, s'apaiser pour pouvoir s'inscrire dans l'ici et le maintenant de la vie... "célébrer ma nouvelle naissance des entrailles de ce pays. Et me dire que je suis enfin guérie". À son arrivée, Mahmoud lui avait promis : "Tu verras, tu vas l'aimer, l'Algérie." 